\title{
Complex Dynamic Analysis for Game Model under Different Regulatory Levels in China's Housing Rental Market
}

\author{
Lingling Mu, ${ }^{1}$ Xiangyu Qin, ${ }^{1}$ Yuan Li, ${ }^{1}$ and Ping Liu $\mathbb{D}^{2}$ \\ ${ }^{1}$ School of Economics and Management, Hebei University of Technology, Tianjin 300401, China \\ ${ }^{2}$ School of Civil and Transportation Engineering, Hebei University of Technology, Tianjin 300401, China \\ Correspondence should be addressed to Ping Liu; 2002lp@hebut.edu.cn
}

Received 5 April 2020; Revised 4 June 2020; Accepted 23 June 2020; Published 26 August 2020

Guest Editor: Lei Xie

Copyright ( $\odot 2020$ Lingling Mu et al. This is an open access article distributed under the Creative Commons Attribution License, which permits unrestricted use, distribution, and reproduction in any medium, provided the original work is properly cited.

In this paper, we construct an evolutionary game model of government and real estate operators (long-term apartment rental companies) in the housing rental market in the context of financial institutions and public participation in regulation and analyze the effects of different regulatory levels of financial institutions and the public on the evolutionary results through model solving and numerical simulation. The results show that, under five different levels of supervision, financial institutions and the public have different evolutionary and stable strategies; financial institutions' participation in supervision can effectively reduce the cost of government supervision and promote the government's evolution towards strict supervision. It is difficult for real estate operators to evolve naturally towards keeping their promises when the probability of the social public or financial institutions participating in regulation is low. Only when the probability of social public and financial institutions participating in regulation reaches a certain level will real estate operators be inclined to keep their promises.

\section{Introduction}

With the advancement of urbanization, the influx of firstand second-tier cities has increased sharply [1]. The "talent policy" in various regions has intensified the demand for urban housing [2]. According to the data in the White Paper on China Housing Leasing in 2018, the current housing rental population is about 168 million, the market size is 1.2 trillion yuan, and the housing lease population will increase by $50 \%$ in the next five years, the market size increased by $150 \%$ [3], and the demand is gradually increasing. However, due to the rising cost of construction and maintenance of rental housing, the low rental return rate makes it difficult for real estate operators to obtain profit [4], and the government does not pay much attention to the housing rental market [5]. The relevant laws and regulations set are not sound, regulatory policies are inadequate [6], and financial institutions and the public are lacking awareness of regulatory reporting, which results in frequent defaults of real estate operators. Therefore, it is necessary and urgent for the government to establish a multibody common regulatory system to regulate the behavior of real estate operators, in order to promote the long-term development of the housing rental market. Therefore, the purpose of this study is to determine what level of regulation should be adopted by both financial institutions and public participation in regulation to promote compliance by real estate operators by exploring the impact of regulation on the evolution of the system.

\section{Literature Review}

It is necessary and urgent to improve the supervision system of China's housing rental market. Wang and $\mathrm{Hu}$ analyzed telephone survey data from four cities in Beijing, Shanghai, Guangzhou, and Shenzhen and found that the housing rental market in first-tier cities in China is not mature enough, and the government needs to strengthen the management of the housing rental market [7]. By combing the development history of the US housing rental policy and comparing it with China's current housing rental policy, Cheng believed that the data of subsidized projects such as China's rent monetary subsidy policy are isolated and have not yet achieved open and transparent monitoring feedback 
[8]. Dou compared the models of coliving communities in Canada and Japan and believed that improving the public participation planning and community governance mechanism is the key driving force for the development of coliving communities in China [9]. Lou and Zhou analyzed the characteristics and existing problems of the Russian housing rental market. They believed that the Russian housing rental management department had weak supervision and rental information, which suggested that the government could cooperate with relevant organizations to improve the supervision ability [10]. By comparing the basic framework and operation mode of the British credit system, Du found that the credit data acquisition of China's housing rental market was not widespread; the mechanism of publicity, use, and protection was not perfect; the regulation ability was insufficient; and the mechanism of rewards and punishments was not perfect. Therefore, he suggested improving the management of the housing rental market based on personal credit [11].

There are conflicts of interest between the participants in the housing rental market [12]. Real estate operators will choose improper means to sacrifice the interests of other subjects, such as lessees, in the pursuit of their own values [13]. The government supervision and coordination mechanism need to be improved. Relevant research on the current government-regulated housing rental market participants shows that, in the development of the housing rental market, the three parties of the government, consumers, and enterprises finally reach a stable balance in the government's nonregulation, consumers tend to rent houses, and enterprises actively develop rental business. The cost of government regulation and the penalties for companies are the main drivers of tripartite evolution [14]. Qiu has developed an evolutionary game model of social forces and the government to address the problem of excessive participation of social forces in the profit-seeking behavior of housing rental projects, which leads to rent increases; the study shows that it is difficult for social forces to evolve naturally without external forces to not participate in illegal rental projects, and the government needs to implement appropriate institutional norms to regulate the behavior of social forces [15]. Zhou et al. constructed the interest game model between the central government and local government in the process of developing rental housing. The key to the development of the housing rental market is to enlarge the utility proportion shared by the local government, reduce the supervision cost of the central government, and increase the punishment for the inaction of the local government [16]. Chai et al. reduced the social interest adjustment mechanism of collective rental housing to the Pareto improvement of land and housing interest production and distribution and then designed the multicenter game competition and synergy mechanism of government, lessee, rural collective, and interest group. He suggested that government should give autonomy to local government systems and technology choices [17]. Lai established a dynamic Cournot model of bounded rational duopoly to verify the government's influence on real estate developers [18].

Scholars have reached a unified opinion on the urgent need to strengthen the supervision of China's housing rental market and analyzed the feasibility of government regulation affecting the choice of real estate operators while ignoring the importance of financial institutions and the public to participate in supervision. Financial institutions and the public are the most direct contacts to the housing rental market. Therefore, this paper incorporates financial institutions and the public into the regulatory system, builds an evolutionary game system in which multiparty entities participate in the supervision of real estate operators' behaviors, analyzes the strategy selection of the government and real estate operators with different participation levels of financial institutions and the public, and explores the impact of financial institutions and the public's participation in supervision on the system evolution.

\section{Evolutionary Game Model}

3.1. Model Description. In the development of the housing rental market, in order to speed up the capital turnover, the long-term apartment rental companies (abbreviated as real estate operators) have the power of illegal operation to earn additional profits and provide houses that do not meet the standards, or use the funds that should be used to serve the lessee for reinvestment, collection of houses, and expansion of income. Financial institutions are providers of funds for real estate operators. In order to prevent real estate operators from using funds in breach of contract, financial institutions regulate real estate operators, which can reduce the cost of supervision by government departments. As beneficiaries of rental housing, the public can have the most direct experience of rental housing provided by real estate operators and understand whether real estate operators are abiding by their contracts. Therefore, it is easier for financial institutions and the public to detect the default of real estate operators, which can effectively reduce the cost of government regulation and expose the default of real estate operators.

In traditional game theory, it is often assumed that participants are bounded rational and that participants are fully informed; however, the problem of incomplete information and bounded rationality is evident due to the complexity of the economic environment [19]. Evolutionary game is studied with a bounded rational group of participants [20-26]. In the continuous dynamic gaming, the lowyield strategy choice is constantly eliminated by the highyield strategy choice; after repeated gaming, elimination, and choice, the gaming parties achieve stability at the relative maximum benefit [27]. The gaming participants in this model are governments and real estate operators who are assumed to be bounded rational "economic man." According to evolutionary game theory, under incomplete information conditions, the government's strategy set is (strict supervision, loose supervision) and the real estate operator's strategy set is (keeping promise, default). Because the participation of financial institutions in the regulation of the housing rental market affects the cost of government regulation, and the participation of the public in the regulation of the housing rental market affects the exposure probability of default by real estate operators, the government-enterprise game in the housing rental market is 
defined as the dynamic game between the government and real estate operators in the context of different levels of participation of financial institutions and the public in regulation.

3.2. Model Assumptions. To analyze the problem, several assumptions are made.

Assumption 1. As the government has introduced some regulatory policies, but not fully implemented in practice, the regulation of the housing rental market is in a relatively lax state [28], and the cost of regulation is set at $c_{0}$. If the government is to strictly implement the corresponding regulatory policies need to pay the corresponding additional regulatory cost $\Delta c$, the involvement of financial institutions in regulation can effectively reduce the cost of regulation when governments adopt a strict regulatory strategy, so the cost of regulation when governments adopt a strict regulatory strategy can be expressed as $c=c_{0}+\Delta c-p k$. $p$ is the probability of financial institutions participating in regulation. $k$, a constant, represents the financial regulatory capacity coefficient. Strict government regulation will enhance the credibility of the government, which can bring benefits to the government as $r_{1}$.

Assumption 2. Real estate operators keeping their promises can enhance social stability, which brings gains to the government as $r_{2}$. Defaults by real estate operators have a negative impact, which brings losses to the government for $\nu$.

Assumption 3. If the real estate operator keeps its promise, it will receive the basic benefits $d$ and the benefits $h$ from public opinion exposure and publicity regarding the good conduct of the business [15]. If the real estate operator defaults, it receives an additional gain $\Delta d$. However, if the government detects the real estate operator's default, it will have to pay a penalty $z$ and suffer a potential loss $\delta$ such as reputational decline.

Assumption 4. The probability of the government identifying default by real estate operator is $\lambda$ and $\lambda^{\prime}$, respectively, when the government chooses strict and loose regulation, and the probability of real estate operators adopting default strategies with the participation of the public and being identified by the government is $\mu=\lambda+q(1-\lambda)$ and $\mu_{0}=\lambda^{\prime}+q\left(1-\lambda^{\prime}\right)$, where $q$ is the probability of the public regulating in the housing rental market. When the government adopts a loose regulatory strategy and the public exposes the real estate operator's default, the government's social credibility will be reduced, and the government will suffer a loss of $n$.

3.3. Model Building. Assume that $x, y, p$, and $q$ $(0<x, y, p, q<1)$ are the probability of strict government supervision, real estate operator compliance, financial institutions' participation in supervision, and public participation in supervision, respectively. The payment matrix of government and real estate operators is shown in Table 1.
The expected benefit of the government choosing strict regulation is

$$
U_{G}^{1}=y\left(r_{1}-c+r_{2}\right)+(1-y)\left(r_{1}-c-v+\mu z\right) .
$$

The expected benefit of the government choosing loose regulation is

$$
U_{G}^{2}=y\left(r_{2}-c_{0}\right)+(1-y)\left(\mu_{0} z-q n\left(1-\lambda^{\prime}\right)-c_{0}-v\right) .
$$

Thus, the average benefit of the government is

$$
\bar{U}_{G}=x U_{G}^{1}+(1-x) U_{G}^{2} .
$$

The replicated dynamic equation dynamic of the government is

$$
\begin{aligned}
F_{G}=\frac{\mathrm{d} x}{\mathrm{~d} t}= & x\left(U_{G}^{1}-\bar{U}_{G}\right) \\
= & x(1-x)\left(c_{0}-c+r_{1}+q n\left(1-\lambda^{\prime}\right)(1-y)\right. \\
& \left.+z(1-y)\left(\mu-\mu_{0}\right)\right), \\
\frac{\partial F_{G}}{\partial x}= & (1-2 x)\left(c_{0}-c+r_{1}+q n\left(1-\lambda^{\prime}\right)(1-y)\right. \\
& \left.+z(1-y)\left(\mu-\mu_{0}\right)\right) .
\end{aligned}
$$

The expected benefit of the real estate operators choosing to keep their promises is

$$
U_{R}^{1}=x(d+h)+(1-x)(d+h) .
$$

The expected benefit of the real estate operator choosing to default is

$U_{R}^{2}=x(d+\Delta d-\mu(z+\delta))+(1-x)\left(d+\Delta d-\mu_{0}(z+\delta)\right)$.

Thus, the average benefit of the real estate operator is

$$
\bar{U}_{R}=y U_{R}^{1}+(1-y) U_{R}^{2} .
$$

The replicated dynamic equation dynamic of the real estate operator is

$$
\begin{aligned}
F_{R} & =\frac{\mathrm{d} y}{\mathrm{~d} t}=y\left(U_{R}^{1}-\bar{U}_{R}\right) \\
& =y(1-y)\left(h-\Delta d+\mu(z+\delta) x+\mu_{0}(z+\delta)(1-x)\right),
\end{aligned}
$$

$$
\frac{\partial F_{R}}{\partial y}=(1-2 y)\left(h-\Delta d+\mu(z+\delta) x+\mu_{0}(z+\delta)(1-x)\right)
$$

\section{Evolutionary Game Analysis}

4.1. Replication Dynamics Analysis of Government DecisionMaking Behavior. From the replicated dynamic equations stability theorem and the nature of the evolutionary stability 
TABle 1: Payment matrix of government and real estate operators.

\begin{tabular}{lcc}
\hline \multirow{2}{*}{ Government } & \multicolumn{2}{c}{ Real estate operator } \\
& Keep promise & Default \\
\hline \multirow{2}{*}{ Strict supervision } & $r_{1}-c+r_{2}$ & $r_{1}-c-v+\mu z$ \\
& $d+h$ & $d+\Delta d-\mu(z+\delta)$ \\
\hline \multirow{2}{*}{ Loose supervision } & $r_{2}-c_{0}$ & $\mu_{0} z-q n 1-\lambda I-c_{0}-v$ \\
& $d+h$ & $d+\Delta d-\mu_{0}(z+\delta)$ \\
\hline
\end{tabular}

strategy, it is known that when the stability strategy $x$ satisfies $F_{G}=0,\left(\partial F_{G} / \partial x\right)<0, x$ is the evolutionary stability strategy. Calculated by $F_{G}=0, y_{0}$ can be represented by the following equation:

$$
y_{0}=\frac{c-c_{0}-r_{1}-q n\left(1-\lambda^{\prime}\right)-z\left(\mu-\mu_{0}\right)}{-q n\left(1-\lambda^{\prime}\right)-z\left(\mu-\mu_{0}\right)} .
$$

When $y=y_{0}, F_{G}$ is constant at zero, which means that the strategies adopted by the government are stable and do not change over time.

If $y_{0}<0$, the probability of financial institutions participating in regulation satisfies the following equation:

$$
p<\frac{\Delta c-r_{1}-\left(\mu-\mu_{0}\right) z-q n\left(1-\lambda^{\prime}\right)}{k}=p_{L} .
$$

Since $y>y_{0}, x=0$ is the evolutionary stability strategy. The government's gains from strict regulation are always less than those from loose regulation, so the government will adopt loose regulation regardless of whether real estate operators keep their promises.

If $y_{0}>1$, the probability of financial institutions participating in regulation satisfies the following equation:

$$
p>\frac{\Delta c-r_{1}}{k}=p_{H} .
$$

Since $y<y_{0}, x=1$ is the evolutionary stability strategy. The government's gains from strict regulation are always more than those from loose regulation, so the government will adopt strict regulation regardless of whether real estate operators keep their promises.

If $0<y_{0}<1$, the probability of financial institutions participating in regulation satisfies the following equation:

$$
\frac{\Delta c-r_{1}-\left(\mu-\mu_{0}\right) z-q n\left(1-\lambda^{\prime}\right)}{k}<p<\frac{\Delta c-r_{1}}{k} \text {. }
$$

The relationship between $y$ and $y_{0}$ needs to be discussed according to different situations. When $y<y_{0}, x=1$ is the evolutionary stability strategy and at this time the government adopts strict regulatory behavior. When $y>y_{0}, x=0$ is the evolutionary stability strategy and at this time the government adopts loose regulatory behavior.

In order to vividly understand the dynamic evolution of government decision-making behavior, we give a graph of the evolution of government decision-making behavior under different circumstances, as shown in Figure 1.
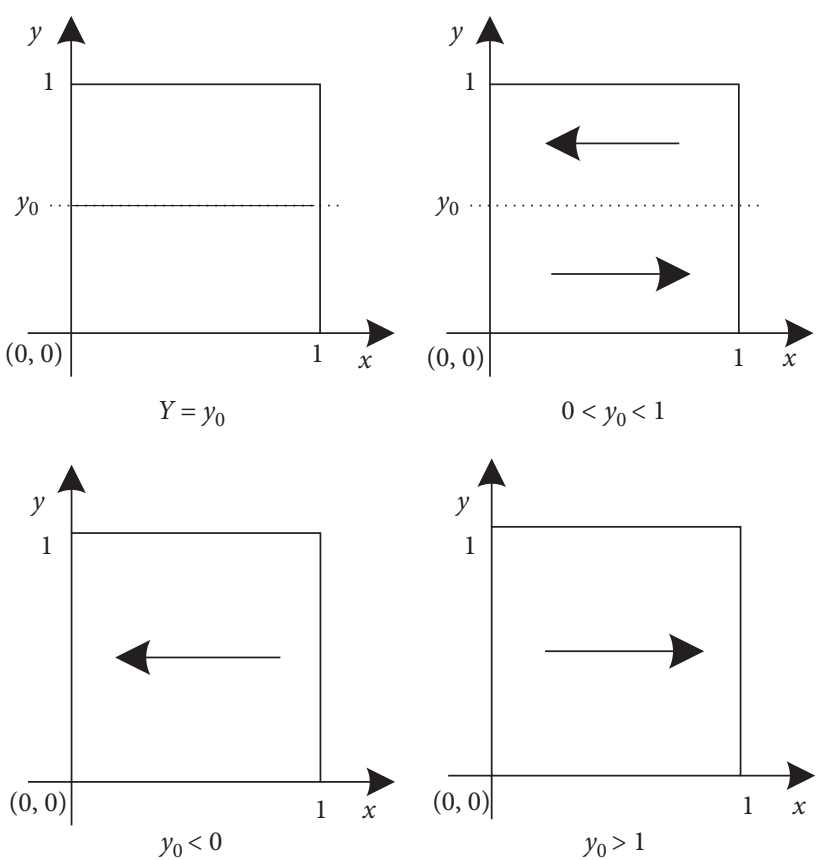

FIGURE 1: Government replication dynamic phase diagram.

equations stability theorem and the nature of the evolutionary stability strategy, it is known that when the stability strategy $y$ satisfies $F_{R}=0,\left(\partial F_{R} / \partial y\right)<0, y$ is the evolutionary stability strategy. Calculated by $\mathrm{F}_{R}=0, \mathrm{x}_{0}$ can be represented by the following equation:

$$
x_{0}=-\frac{h-\Delta d+\mu_{0}(z+\delta)}{\left(\mu-\mu_{0}\right)(z+\delta)} \text {. }
$$

When $x=x_{0}, F_{R}$ is constant at zero, which means that the strategies adopted by the real estate operators are stable and do not change over time.

If $x_{0}<0$, the probability of financial institutions participating in regulation satisfies the following equation:

$$
q>\frac{\Delta d-h-\lambda(z+\delta)}{(1-\lambda)(z+\delta)}=q_{H}
$$

Since $x>x_{0}, y=1$ is the evolutionary stability strategy. The real estate operators' gains from keeping their promises are always more than those from default. So, no matter what regulatory actions the government takes, real estate operators keep their promises.

If $x_{0}>1$, the probability of public participation in regulation satisfies the following equation:

$$
q<\frac{\Delta d-h-\lambda^{\prime}(z+\delta)}{\left(1-\lambda^{\prime}\right)(z+\delta)}=q_{L}
$$

Since $x<x_{0}, y=0$ is the evolutionary stability strategy. The real estate operators' gains from keeping their promises are always less than those from default. So, no matter what regulatory actions the government takes, real estate operators are in default.

If $0<x_{0}<1$, the probability of public participation in regulation satisfies the following equation: 


$$
\frac{\Delta d-h-\lambda^{\prime}(z+\delta)}{\left(1-\lambda^{\prime}\right)(z+\delta)}<q<\frac{\Delta d-h-\lambda(z+\delta)}{(1-\lambda)(z+\delta)} .
$$

The relationship between $x$ and $\mathrm{x}_{0}$ needs to be discussed according to different situations. When $x<x_{0}, y=0$ is the evolutionary stability strategy and at this time real estate operators adopt default behaviors. When $x>x_{0}, y=1$ is the evolutionary stability strategy and at this time real estate operators keep their promises.

In order to vividly understand the dynamic evolution of government decision-making behavior, we give a graph of the evolution of government decision-making behavior under different circumstances, as shown in Figure 2.

4.3. Stability Analysis of Equilibrium Point. Since the above equilibrium point is not necessarily the system's evolutionary stability strategy (ESS), according to the computational differential equations proposed by Friedman to form the dynamics of the dynamic system, the stability analysis of the equilibrium point can be analyzed by analyzing the local stability of the Jacobian matrix of the system. Solving the partial derivatives of $x$ and $y$ for the differential equations (4) and (9) sequentially, the Jacobian matrix can be obtained as

$$
J=\left[\begin{array}{ll}
\frac{\partial F_{G}}{\partial x} & \frac{\partial F_{G}}{\partial y} \\
\frac{\partial F_{R}}{\partial x} & \frac{\partial F_{R}}{\partial y}
\end{array}\right]=\left[\begin{array}{ll}
J_{11} & J_{12} \\
J_{21} & J_{22}
\end{array}\right],
$$

$J_{11}=(1-2 x)\left(c_{0}-c+r_{1}+\left(q n\left(1-\lambda^{\prime}\right)+z\left(\mu-\mu_{0}\right)\right)(1-y)\right.$,

$J_{12}=x(x-1)\left(q n\left(1-\lambda^{\prime}\right)+z\left(\mu-\mu_{0}\right)\right)$,

$J_{21}=y(1-y)\left(\mu-\mu_{0}\right)(z+\delta)$,

$J_{22}=(1-2 y)\left(h-\Delta d+(z+\delta)\left(\mu x+\mu_{0}(1-x)\right)\right)$.

The calculation process of the determinant $\operatorname{det}_{J}$ and the $\operatorname{tr}_{J}$ trace of the Jacobian matrix is as follows:

$$
\begin{aligned}
\operatorname{det}_{J}= & x(1-x)\left(q n\left(1-\lambda^{\prime}\right)+z\left(\mu-\mu_{0}\right)\right) y(1-y)\left(\mu-\mu_{0}\right) \\
& \cdot(z+\delta)+(1-2 x) c_{0}-c+r_{1}+\left(q n\left(1-\lambda^{\prime}\right)+z\left(\mu-\mu_{0}\right)\right) \\
& \cdot(1-2 y)\left(h-\Delta d+(z+\delta)\left(\mu x+\mu_{0}(1-x)\right)\right), \\
\operatorname{tr}_{J}= & (1-2 x) c_{0}-c+r_{1}+\left(q n\left(1-\lambda^{\prime}\right)+z\left(\mu-\mu_{0}\right)\right) \\
& \cdot(1-y)+(1-2 y)\left(h-\Delta d+(z+\delta)\left(\mu x+\mu_{0}(1-x)\right)\right) .
\end{aligned}
$$

If the equilibrium point satisfies $\operatorname{det}_{J}>0$ and $\operatorname{tr}_{J}<0$, the equilibrium point is the local asymptotic stability point of the evolutionary dynamic process. In this paper, we discuss the parameter conditions from the evolutionary path of the government and the real estate operator, combined with the mathematical point of view and practical significance, and conclude that the dynamic system needs to analyze the local stability under the following nine parameter conditions, as shown in Tables 2-6.
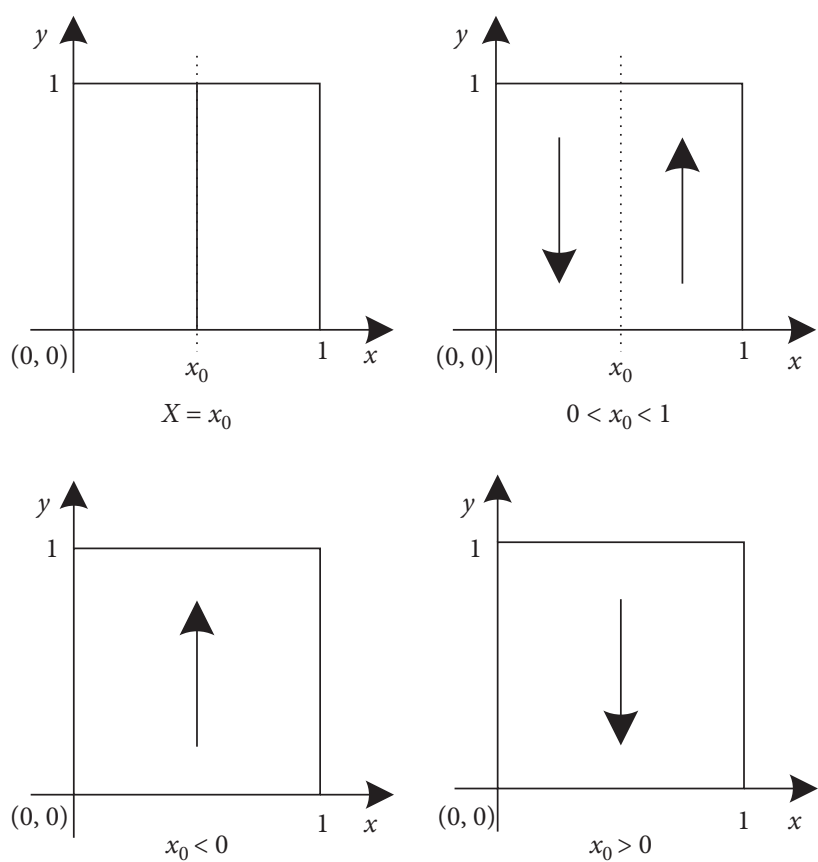

Figure 2: Replication dynamic phase diagram of the real estate operator.

\subsection{Result Analysis}

4.4.1. Scenario 1. When the probability of financial institutions and the public participating in supervision is $p<p_{L}$ and $q<q_{H}$, respectively, and the government benefits less than the regulatory cost by adopting a strict regulatory strategy, the government tends to adopt a loose supervision strategy. The low probability of public participation in regulation makes defaults by real estate operators less susceptible to detection, and the damage to the operator's reputation and government penalties are less than the gains in the event of default, so real estate operators tend to choose default. In this case, the evolutionary equilibrium strategy is $(0,0)$.

4.4.2. Scenario 2. When the probability of financial institutions and the public participating in supervision is $p_{L}<p$ and $q<q_{L}$, respectively, the participation of financial institutions in regulation can reduce the cost of government regulation and therefore the government tends to adopt strict regulatory measures. However, the probability of public participation in regulation is low, and the investigation and punishment of real estate operators' defaults mainly rely on government regulation. Real estate operators choose to default because the penalty for default is less than the proceeds they would have received if they had defaulted. So in this case, the evolutionary equilibrium strategy is $(1,0)$.

4.4.3. Scenario 3. When the probability of financial institutions and the public participating in supervision is $p<p_{H}$ and $q>q_{H}$, respectively, the high probability of social public 
TABLE 2: Equilibrium point local stability.

\begin{tabular}{lccccc}
\hline Equilibrium & & $\mathbf{p}<\mathbf{p}_{\mathbf{L}}, \mathbf{q}>\mathbf{q}_{\mathbf{H}}$ & & \multicolumn{2}{c}{$\mathbf{p}<\mathbf{p}_{\mathbf{L}}, \mathbf{q}<\mathbf{q}_{\mathbf{L}}$} \\
& $\operatorname{det} J$ & $\operatorname{tr} j$ & Stability & $\operatorname{det} J$ & Stability \\
\hline$(0,0)$ & - & Uncertain & Saddle point & + & ESS \\
$(0,1)$ & + & - & ESS & - & Uncertain \\
$(1,0)$ & + & + & Unstable & - & Uncertain \\
$(1,1)$ & - & Uncertain & Saddle point & + & Saddle point \\
\hline
\end{tabular}

TABLE 3: Equilibrium point local stability.

\begin{tabular}{lcccccc}
\hline Equilibrium & & $\mathbf{p}<\mathbf{p}_{\mathbf{L}}, \mathbf{q}_{\mathbf{L}}<\mathbf{q}<\mathbf{q}_{\mathbf{H}}$ & & \multicolumn{2}{c}{$\mathbf{p}_{\mathbf{L}}<\mathbf{p}<\mathbf{p}_{\mathbf{H}}, \mathbf{q}>\mathbf{q}_{\mathbf{H}}$} \\
& $\operatorname{det} J$ & $\operatorname{tr} j$ & Stability & $\operatorname{det} J$ & Stability \\
\hline$(0,0)$ & + & - & ESS & + & Unstable \\
$(0,1)$ & - & Uncertain & Saddle point & + & - & ESS \\
$(1,0)$ & + & + & Unstable & - & Uncertain & Saddle point \\
$(1,1)$ & - & Uncertain & Saddle point & - & Uncertain & Saddle point \\
\hline
\end{tabular}

TABle 4: Equilibrium point local stability.

\begin{tabular}{lcccccc}
\hline \multirow{2}{*}{ Equilibrium } & & $\mathbf{p}_{\mathbf{L}}<\mathbf{p}<\mathbf{p}_{\mathbf{H}}, \mathbf{q}<\mathbf{q}_{\mathbf{L}}$ & & & \multicolumn{2}{c}{$\mathbf{p}>\mathbf{p}_{\mathbf{H}}, \mathbf{q}>\mathbf{q}_{\mathbf{H}}$} \\
& $\operatorname{det} J$ & $\operatorname{tr} j$ & tr $j$ & Stability & $\operatorname{det} J$ & Unstable \\
\hline$(0,0)$ & - & Uncertain & Saddle point & + & Stability \\
$(0,1)$ & - & Uncertain & Saddle point & - & Uncertain & Saddle point \\
$(1,0)$ & + & - & ESS & - & Uncertain & Saddle point \\
$(1,1)$ & + & + & Unstable & + & - & ESS \\
\hline
\end{tabular}

TABLE 5: Equilibrium point local stability.

\begin{tabular}{|c|c|c|c|c|c|c|}
\hline \multirow{2}{*}{ Equilibrium } & \multicolumn{3}{|c|}{$\mathbf{p}>\mathbf{p}_{\mathrm{H}}, \mathbf{q}<\mathbf{q}_{\mathrm{L}}$} & \multicolumn{3}{|c|}{$\mathbf{p}>\mathbf{p}_{\mathrm{H}}, \mathbf{q}_{\mathrm{L}}<\mathbf{q}<\mathbf{q}_{\mathrm{H}}$} \\
\hline & $\operatorname{det} J$ & $\operatorname{tr} j$ & Stability & $\operatorname{det} J$ & $\operatorname{tr} j$ & Stability \\
\hline$(0,0)$ & - & Uncertain & Saddle point & - & Uncertain & Saddle point \\
\hline$(0,1)$ & + & + & Unstable & + & + & Unstable \\
\hline$(1,0)$ & + & - & ESS & - & Uncertain & Saddle point \\
\hline$(1,1)$ & - & Uncertain & Saddle point & + & - & ESS \\
\hline
\end{tabular}

TABLE 6: Equilibrium point local stability.

\begin{tabular}{lccr}
\hline Equilibrium & & $\mathbf{p}_{\mathbf{L}}<\mathbf{p}<\mathbf{p}_{\mathbf{H}}, \mathbf{q}_{\mathbf{L}}<\mathbf{q}<\mathbf{q}_{\mathbf{H}}$ & Stability \\
& $\operatorname{det} J$ & $\operatorname{tr} j$ & Saddle point \\
$(0,0)$ & - & Unstable & Saddle point \\
$(0,1)$ & - & Unstable & Saddle point \\
$(1,0)$ & - & Unstable & Saddle point \\
$(1,1)$ & - & Unstable & Saddle point \\
$\left(\mathbf{X}_{0}, \mathbf{Y}_{0}\right)$ & 0 & 0 & Sable \\
\hline
\end{tabular}

participation in regulation leads to a higher probability of exposure of the real estate operator to default, and therefore it is more likely to be penalized by the government and to suffer reputational damage. The real estate operator's gains when keeping its promise are greater than those when it defaults, so real estate operator tends to keep its promise. The increased probability of default exposure makes it easier for the government to detect defaults by real estate operators, so the government tends to choose lax regulation. In this case, the evolutionary equilibrium strategy is $(0,1)$.

4.4.4. Scenario 4. When the probability of financial institutions and the public participating in supervision is $p>p_{H}$ 
and $q_{L}<q$, respectively, financial institution participation reduces the expected costs that governments adopt strict regulation, so governments tend to adopt strict regulation strategies. The high probability of financial institutions participating in regulation enhances government enforcement against real estate operators, so when public participation in regulation is at a superior level, the government penalties for default and reputational damage to real estate operators will outweigh the gains from compliance. So, in this case, the evolutionary equilibrium strategy of the game is $(1,1)$.

4.4.5. Scenario 5. When the probability of financial institutions and the public participating in supervision is $p_{L}<p<p_{H}$ and $q_{L}<q<q_{H}$, respectively, the probability of financial institutions and the public participating in regulation is low, which has limited impact on the strategic choices of governments and real estate operators. As a result, the government and real estate operators have not reached the stability strategy, and the evolutionary result is a cyclical random state that belongs to the chaotic period of government and real estate operator strategy selection.

4.5. Numerical Simulation. In this section we use numerical simulations to illustrate in detail the impact of different levels of financial institutions and social public participation in regulation on the decisions of governments and real estate operators. This paper assumes that $r_{1}=0.2, r_{2}=1, v=1$, $z=1, \quad n=1, \quad \lambda=0.5, \quad \lambda^{\prime}=0.3, \quad d=1, \quad \Delta d=2.5, \quad \delta=1$, $\Delta c=1, k=1$. Due to the lack of recognizing the behavior of real estate operator awareness, the government adopts a more relaxed regulatory strategy, which leads to frequent defaults of real estate operators. Therefore, this paper assumes that the initial values of $x$ and $y$ are $x=0.2$ and $y=0.2$, respectively.

A schematic of the strategy evolution when the government and real estate operator strategies are $p=0.3, q=0.55$, respectively, is shown in Figure 3(a), which validates the analysis results of Scenario 1. The figure shows that the final evolutionary strategy of the government and real estate operators is $(0,0)$ when financial regulation is at a low level and public participation is at a medium to low level. The probability of financial institutions participating in regulation increases in comparison Scenario 1 , that is, $p=0.7, q=0.55$, and the government's behavior tends to choose a strict regulatory strategy. However, due to the moderate level of regulation of financial institutions and public participation in society, the game between the government and real estate operator shows a cyclical state and the evolutionary results can be seen in Figure 3(b). The probability of social public participation in regulation increases to a high level in comparison to Scenario 5, that is, $p=0.7, q=0.7$, and the increase in the exposure of default leads the real estate operator to choose to keep its promise. The evolutionary results can be seen in Figure 3(c). The probability of social public participation in regulation is reduced to a low level in comparative Scenario 5, that is, $p=0.7, q=0.4$. The reduction in the exposure to default causes the real estate operator to choose to default, and the evolutionary results can be seen in Figure 3(d). The probability of financial institutions participating in the regulation increased to a high level, that is, $p=0.81, q=0.55$, which can effectively reduce the pressure of government regulation, the government tends to choose strict regulation. At this point, real estate operator tends to keep its promise under strict government regulation and a higher level of social public regulation, and the evolutionary results can be seen in Figure 3(e).

\section{Discussion}

Through the analysis and simulation of evolutionary results, the article illustrates the impact of different levels of financial institutions and social public participation in regulation on the decision-making behavior of governments and real estate operators. The strong regulatory awareness of financial institutions or the public will lead real estate operator to keep its promise, but if the regulatory awareness of the public is weak, the public will be less exposed to the operators' violations, and thus the strong regulatory awareness of financial institutions will not lead real estate operators to keep their promises. However, the public with a high level of supervision will expose the real estate operator's default to a great extent, which results in significant default costs for real estate operators, including government penalties and reputational damage. Therefore, the real estate operator must choose to keep its promise. Public participation in regulation is particularly important for the governance of China's housing rental market. The combination of financial institutions and the public is important for maximizing regulatory effectiveness.

There are four types of regulatory subjects involved in our study, including the government, financial institutions, and the public in the housing rental market. However, Qiu [15] and Zheng and Xu [14] argue that the government is the only entity involved in regulation in the housing rental market. Their study found that different government regulation behaviors is the key to guide firms to produce different decision behaviors, and that changes in government incentives and penalties can have an impact on the evolutionary path of firms' behavior. Zhou et al. [16] also found that reducing the cost of regulation can change the evolutionary path of the regulated behavior. Based on previous studies involving government incentives and penalties, we also set incentives and penalties in our study. However, today is the age of information technology. The popularity of mobile devices, the development of network technology, and the construction of big data provide new ways and means for the public and financial institutions to participate in regulation. The multidominant participatory regulatory model becomes an important way of regulatory governance. In contrast to related research, our study finds that in the case of multiagency regulation, real estate operators can choose to keep their promises even if the government does not need to change its regulatory measures. 


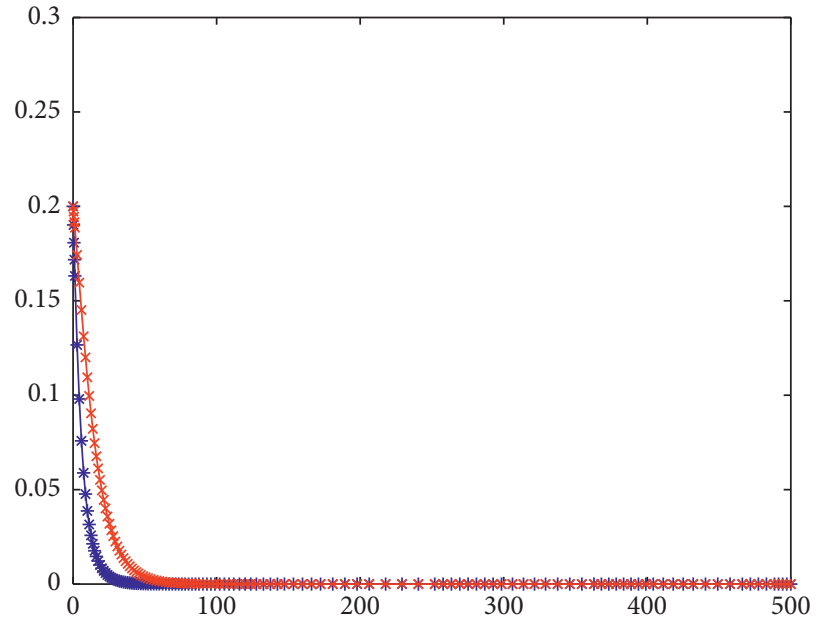

* Government

$\star \star$ Real estate operator

(a)

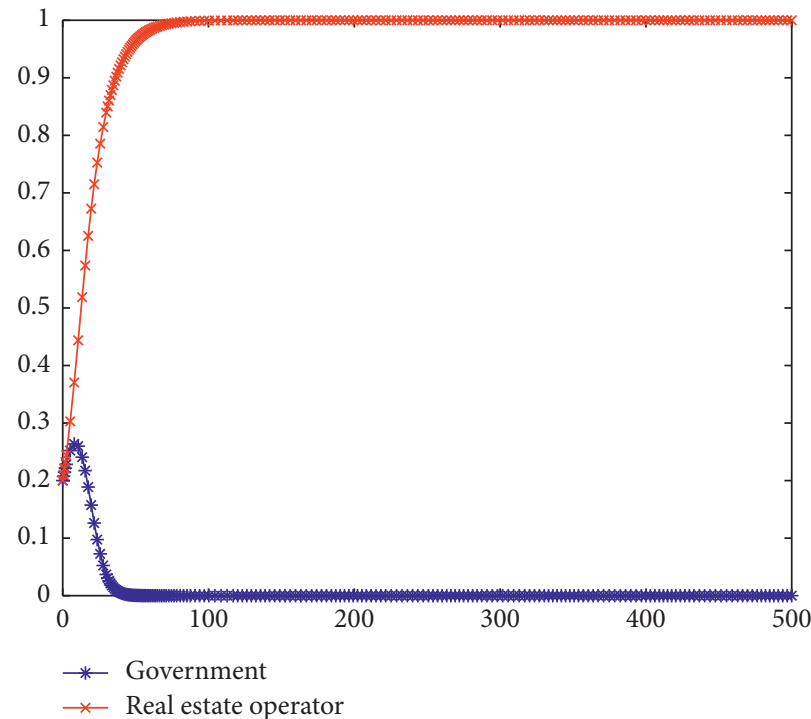

(c)

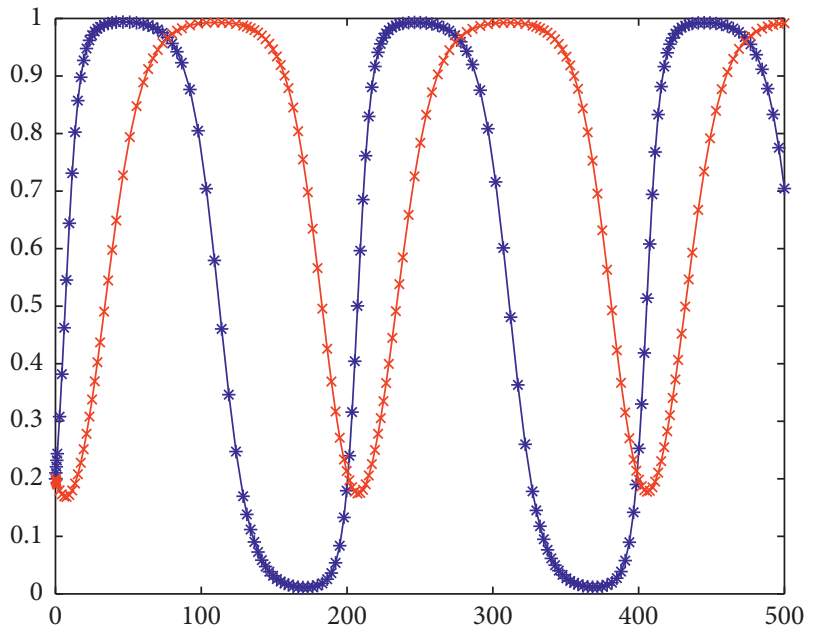

* Government

$\star$ * Real estate operator

(b)

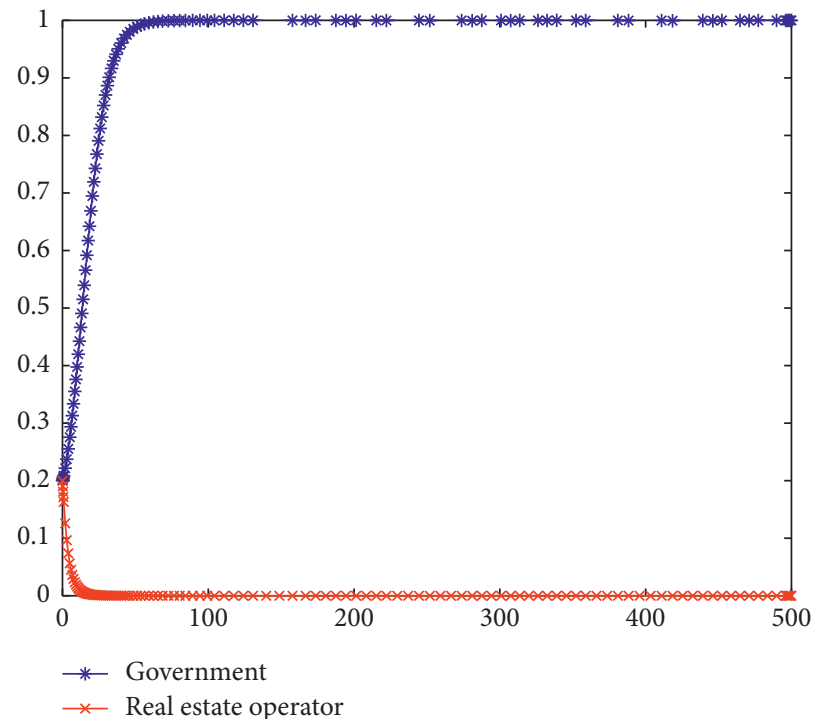

(d)

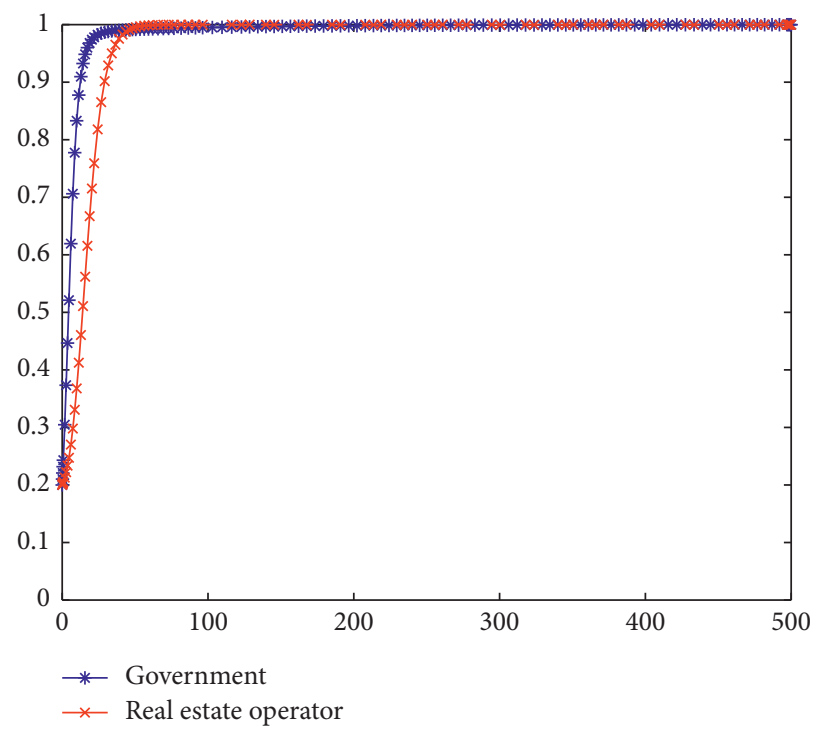

(e)

FiguRE 3: Government's and real estate operators' strategic evolutionary roadmaps with different levels of financial institutions and public involvement in regulation. 


\section{Implications}

In this paper, we construct an evolutionary game system in which multiple subjects are involved in monitoring the behavior of real estate operators and analyze the strategic choices of government and real estate operators with different levels of participation by financial institutions and the public in society. This paper draws conclusions from both theoretical and practical perspectives.

From a theoretical perspective, the implications are as follows. We find that the level of regulatory involvement of financial institutions and the public at large is complex in its impact on the strategies of governments and real estate operators. If one of the financial institutions and the public is involved in regulation at a low level, the real estate operator will default. If the probability of public participation in regulation is high, regardless of the level of financial institutions' participation in regulation, real estate operators will ultimately choose to keep their promises. However, real estate operators will only choose to be compliant if the probability of financial institutions participating in regulation is high and the probability of requiring community participation in regulation is at a medium level and above.

From a practical perspective, we propose several conclusions. In contrast to the involvement of financial institutions in regulation, social and public participation in regulation is essential for the healthy development of China's housing rental market. Therefore, in order to strengthen public participation in regulation, the government can simplify the process of reporting violations in the housing rental market, broaden the reporting channels, and strictly scrutinize reports from the public once received. In order to facilitate public participation, the government can build a platform for information disclosure and sharing and regularly check public messages and provide timely responses. In contrast to a single public regulation, the participation of financial institutions and the public in regulation is conducive to a higher level of regulation. Therefore, in order to improve the level of regulation, the government can reduce the default risk for real estate operators by requiring companies to hand over their pools to third-party banks for management.

\section{Data Availability}

All data used have been included in this article and are also available from the corresponding author upon request.

\section{Conflicts of Interest}

The authors declare no conflicts of interest.

\section{Acknowledgments}

This research was supported by the National Natural Science Foundation of China (no. 71904042). The authors would like to thank Shihao Zhou who helped them in using MATLAB software and Masese Duke for correcting grammar mistakes in this paper.

\section{References}

[1] L. Bi, Y. Fan, M. Gao, C. L. Lee, and G. Yin, "Spatial mismatch, enclave effects and employment outcomes for rural migrant workers: empirical evidence from Yunnan Province, China," Habitat International, vol. 86, pp. 48-60, 2019.

[2] S. Zheng, Y. Cheng, and Y. Ju, "Understanding the intention and behavior of renting houses among the young generation: evidence from jinan, China," Sustainability, vol. 11, no. 6, p. 1507, 2019.

[3] Shell institute, "A white paper on housing rental in china in 2018," 2018, https:/www.useit.com.cn/thread-20115-1-1. html.

[4] R. Collinson, "Rental housing affordability dynamics, 19902009," Cityscape, vol. 13, no. 2, pp. 71-103, 2011.

[5] J. Shi, K. Duan, S. Wen, and R. Zhang, "Investment valuation model of public rental housing PPP project for private sector: a real option perspective," Sustainability, vol. 11, no. 7, p. 1857, 2019.

[6] X. Yi and L. Zheng, "The major theoretical issues of the sustainable development of China's residential housing rental market," Exploration and Free Views, vol. 2, pp. 117-144, 2019.

[7] W. Wang and Y. Hu, "Research on housing rental market in first-tier cities," The World of Survey and Research, vol. 4, pp. 25-30, 2019.

[8] C. Lv, "Research on the "market priority" rental policy in the United States," On Economic Problems, vol. 2, pp. 19-26, 2019.

[9] R. Dou, "A comparative study between Canadian and Japanese cohousing modes and related experience: based on the features of system building, space arrangement, and operations management," City Planning Review, vol. 42, no. 11, pp. 111-123, 2018.

[10] W. Lou and H. Zhou, "Experience of Russian housing rental market reform and reference," Price: Theory \& Practice, vol. 11, pp. 58-61, 2018.

[11] L. Du, "Learning from the credit mechanism of the British housing leasing market," Frontiers, vol. 19, pp. 70-78, 2018.

[12] J. Yuan, W. Li, X. Zheng, and M. J. Skibniewski, "Improving operation performance of public rental housing delivery by PPPs in China," Journal of Management in Engineering, vol. 34, no. 4, Article ID 04018015, 2018.

[13] T. Yu, X. Liang, G. Q. Shen, Q. Shi, and G. Wang, "An optimization model for managing stakeholder conflicts in urban redevelopment projects in China," Journal of Cleaner Production, vol. 212, pp. 537-547, 2019.

[14] S. Zheng and S. Xu, "Co-evolutionary simulation analysis of multiple stakeholders in the housing rental market based on system dynamics," Journal of Engineering Management, vol. 32, no. 6, pp. 149-154, 2018.

[15] J. Qiu, "The game of social forces participating in the evolution of the housing rental market and government regulation," American Journal of Industrial and Business Management, vol. 10, no. 01, pp. 99-109, 2020.

[16] J. Zhou, Y. Zhao, and F. Jv, "The static game and solution strategy in the development of housing rental market and its solution strategy," Seeker, vol. 3, pp. 72-76, 2016.

[17] D. Chai, M. Lin, and H. Fan, "The benefit impacts and multicenter governance mechanism of rental-housing in collective land," Economic Geography, vol. 38, no. 8, pp. 152-161, 2018.

[18] C. Lai and X. Chen, "Complex dynamic analysis for a realestate oligopoly game model with bounded rationality," Journal of Systems Engineering, vol. 28, no. 3, pp. 285-296, 2013. 
[19] B. Xin, F. Cao, W. Peng, and A. A. Elsadany, "A bertrand duopoly game with long-memory effects," Complexity, vol. 2020, Article ID 2924169, , 2020.

[20] B. Xin and M. Sun, "A differential oligopoly game for optimal production planning and water savings," European Journal of Operational Research, vol. 269, no. 1, pp. 206-217, 2018.

[21] J. Ma, F. Zhang, and B. Bao, "Dynamic game and coordination strategy of multichannel supply chain based on brand competition," Complexity, vol. 2019, pp. 1-26, 2019.

[22] Z. Guo, "Complexity and implications on channel conflict under the uncertain impacts of online customer reviews," Nonlinear Dynamics, vol. 96, no. 3, pp. 1971-1987, 2019.

[23] A. A. Elsadany, "Competition analysis of a triopoly game with bounded rationality," Chaos, Solitons \& Fractals, vol. 45, no. 11, pp. 1343-1348, 2012.

[24] F. Tramontana and A. E. A. Elsadany, "Heterogeneous triopoly game with isoelastic demand function," Nonlinear Dynamics, vol. 68, no. 1-2, pp. 187-193, 2011.

[25] R. K. Ghaziani, W. Govaerts, and C. Sonck, "Resonance and bifurcation in a discrete-time predator-prey system with Holling functional response," Nonlinear Analysis: Real World Applications, vol. 13, no. 3, pp. 1451-1465, 2012.

[26] W. Govaerts and R. Khoshsiar Ghaziani, "Stable cycles in a cournot duopoly model of kopel," Journal of Computational and Applied Mathematics, vol. 218, no. 2, pp. 247-258, 2008.

[27] R. Liao, "Customs supervision based on evolutionary game of heterogeneous groups in super-network," System Engineering, vol. 36, no. 8, pp. 140-147, 2018.

[28] L. Li and S. Chen, "An analysis of the policy structure of nurturing and developing the housing rental market - based on a dual perspective of policy instruments and industry chains," Fujian Forum (Humanities and Social Sciences Edition), vol. 8, pp. 28-37, 2018. 